\title{
Atlas dos beneficiários da reforma agrária
}

\author{
MARIA BEATRIZ DE ALBUQUERQUE DAVID \\ PHILIPPE WANIEZ e VIOLETTE BRUSTLEIN
}

\author{
A política \\ de reforma agrária
}

$\mathrm{N}$

AS ÚLTIMAS DÉCADAS, os programas de colonização, a regularização fundiária e a desapropriação - esta última principalmente a partir de 1985 - foram as formas tradicionalmente utilizadas para enfrentar a questão do acesso à terra no Brasil. Na realidade, essas formas de acesso à terra têm sido empregadas mais para atender às pressões sociais e políticas, freqüentemente explosivas, do que visando obter um desenvolvimento rural duradouro, relacionado aos incrementos sustentados da produção, da produtividade e do emprego, que resultariam em melhorias na qualidade de vida da população. Hoje, em um momento em que a demanda por terra exige uma política agrária muito mais criativa e efetiva, novas formas de acesso à terra têm sido propostas, tais como o arrendamento, o leilão de terras e o crédito fundiário.

Um programa de reforma agrária que busque transformar as condições de vida de seus beneficiários deve estar inserido em uma estratégia produtiva que assegure a sustentabilidade desta agricultura. Esta deve ser pensada não somente como meio de sobrevivência das famílias mas, principalmente, como fonte geradora de excedentes que assegurem novos investimentos e permitam a ampliação da produção e da produtividade da agricultura brasileira.

\section{Histórico recente da política agrária}

O processo de democratização e o retorno ao regime civil propiciaram um clima favorável ao ressurgimento das reivindicações em torno da reforma agrária. $\mathrm{O}$ Movimento dos Trabalhadores Rurais Sem Terra (MST) e a Confederação dos Trabalhadores na Agricultura (Contag) puderam, desde esta época e até hoje, aumentar significativamente suas representatividades. A mudança de regime foi acompanhada pelo lançamento de um ambicioso programa de reforma agrária (o Primeiro Plano Nacional de Reforma Agrária), que previa beneficiar mais de um milhão de

* O texto, os mapas e os gráficos deste foram extraídos do documento Os beneficiários da reforma agrária no Brasil, de Maria Beatriz de Albuquerque, Davi Waniez e Violette Brustlein. 
agricultores sem-terra por meio de desapropriações essencialmente no centro-sul do país. O governo Sarney (1985-1990) havia fixado, inicialmente, a meta de dar acesso à propriedade da terra a 1,4 milhão de famílias, mas beneficiou efetivamente apenas 90 mil, menos de $6 \%$ do total pretendido (1). Durante o governo Collor (1990-1992), no qual prometeu-se inicialmente terra a 500 mil famílias, foram praticamente interrompidos tanto o processo de inscrição de novas terras ao cadastro como novas desapropriações (2). Neste período, somente 23 mil famílias receberam o título de propriedade de terras, provenientes do estoque deixado pelo governo precedente. O governo de Itamar Franco (1992-1994), que havia previsto dar acesso à terra a 20 mil famílias em 1993 e a 60 mil em 1994, beneficiou somente 12.600 famílias (3). Em seu programa de governo, o atual presidente havia previsto distribuir 400 mil títulos de propriedade mas, após sua eleição, este objetivo de campanha foi reduzido à meta de beneficiar 260 mil famílias nos quatro anos de seu mandato (1995-1998) (4). Em seu primeiro ano de governo (1995), foram assentadas 42.912 famílias (5); em 1996, 62.044 famílias (6); em 1997, de janeiro a agosto, mais 21 mil famílias foram assentadas, deixando antever que a meta fixada para 1997 (80 mil famílias assentadas) dificilmente será cumprida.

Tabela 1

Número de famílias beneficiadas pelos programas de reforma agrária

\begin{tabular}{|l|l|c|c|c|c|}
\hline Período & \multicolumn{1}{|c|}{ Governo } & $\begin{array}{c}\text { Famílias } \\
\text { beneficiadas por } \\
\text { projetos de } \\
\text { colonização }\end{array}$ & $\begin{array}{c}\text { Famílias } \\
\text { beneficiadas } \\
\text { por programas } \\
\text { de regularização } \\
\text { de títulos }\end{array}$ & $\begin{array}{c}\text { Famílias } \\
\text { beneficiadas por } \\
\text { assentamentos } \\
\text { de R.A. }\end{array}$ & $\begin{array}{c}\text { Total de } \\
\text { famílias } \\
\text { beneficiadas }\end{array}$ \\
\hline $\begin{array}{l}1964-1984 \\
1985-1995\end{array}$ & $\begin{array}{l}\text { Regime autoritário } \\
\text { Sarney, Collor } \\
\text { e Itamar } \\
\text { Fernando Henrique }\end{array}$ & 115 mil & 113 mil & - & 228.0 \\
\hline
\end{tabular}

O recenseamento da reforma agrária: análise crítica e metodologia de elaboração dos mapas para o Atlas

\section{O recenseamento efetuado: criticas e limitações}

No Brasil, onde a questão agrária tem sido objeto de lutas sociais e políticas intensas, a ausência de uma base de dados confiáveis sobre este assunto limita o debate democrático. A falta de informações suficientes conduz também à tomada 
de posições muitas vezes maniqueístas, tanto do lado dos defensores dos agricultores sem-terra como do de seus opositores, em especial os grandes proprietários e seus aliados. É bem verdade que os recenseamentos agropecuários apresentam uma primeira aproximação quantitativa, notadamente sobre a utilização efetiva do solo, mas não permitem avaliar os resultados da política de reforma agrária praticada pelo governo brasileiro e, menos ainda, identificar o que resta a empreender neste campo.

Em decorrência de uma demanda do Incra, que desejava identificar todas as famílias instaladas nas áreas dos projetos, realizou-se um recenseamento dos projetos de reforma agrária. A metodologia utilizada foi a de um recenseamento exaustivo, visando principalmente atualizar as fichas do Incra, ou seja, identificar as famílias e coletar dados sobre características elementares, tais como estado civil, sexo, nível de escolaridade etc. Embora o recenseamento tenha permitido, ao menos de maneira parcial, obter essas informações, é de lamentar que se tenha perdido a oportunidade de abordar certos aspectos importantes do problema agrário. Por exemplo, não se dispõe de nenhuma informação sobre as parcelas ou lotes e sua utilização com culturas ou pastagens. Para preencher essas lacunas, o recenseamento foi complementado por uma pesquisa por amostragem, referente a nove mil explorações, destinada a avaliar os recursos disponíveis e os aspectos produtivos. As condições sociais e o acesso aos serviços médicos e educativos foram também objeto dessa mesma pesquisa por amostragem, realizada em conjunto com o recenseamento.

A realização do recenseamento propriamente dito enfrentou inúmeras dificuldades materiais, decorrentes principalmente de problemas institucionais do Incra: desatualização ou mesmo inexistência de listas de beneficiários e mapas dos limites dos projetos, meios de locomoção deficientes etc. Apesar de conhecer as dificuldades de acesso ao campo no período das chuvas, o Incra definiu o prazo de realização do censo coincidindo com a estação de chuvas. Outro fator que influenciou negativamente o trabalho de recenseamento e, portanto, a qualidade das informações, foi o prazo escasso de dois meses estipulado pelo Ministério Extraordinário de Política Fundiária para sua realização. Todos esses problemas são claramente expostos no relatório executivo (I Censo da Reforma Agrária do Brasil-Relatório Final) e explicam as restrições que pesam sobre os dados coletados.

O recenseamento foi realizado em 1.460 projetos oficiais de reforma agrária delimitados pelo Incra, existentes em 31 de outubro de 1996, e permitiu identificar 199.218 beneficiários, dos quais 161.556 estavam presentes em suas parcelas e puderam ser entrevistados. O relatório executivo (I Censo da Reforma Agrária do Brasil-Relatório Final) apresenta as tabelas estatísticas resultantes de uma primeira exploração, tanto do recenseamento como da pesquisa por amostragem, feitas pelos coordenadores do censo. Ele fornece os dados em nível agregado, ou seja, o país em seu conjunto, e apenas algumas informações em nível estadual.

O trabalho de campo do recenseamento foi feito, em grande parte, no final do ano de 1996 e contou com a participação de 29 universidades coordenadas pela 
UnB. A diferença verificada entre os dados do Incra sobre a estimativa do número de famílias assentadas e os fornecidos pelo censo deve-se, em grande parte, a que o número de famílias que constavam nas informações do instituto representava a capacidade de assentamento por projeto, e não o de famílias efetivamente assentadas. Portanto, em média $25 \%$ das famílias não foram encontradas, em muitos casos simplesmente porque nunca chegaram a ser assentadas, em outros pela própria dificuldade de acesso aos projetos de assentamento ou ainda pela recusa de algumas famílias em responder os questionários. Em alguns lugares, especialmente no Sul, a presença de agregados era bastante significativa, superando assim os números totais de pessoas que constavam dos cadastros. $\mathrm{O}$ abandono dos lotes nos assentamentos mais antigos da região Norte chega a $30 \%$. A maioria dos beneficiários tem na atividade rural sua ocupação principal. A forma de exploração do lote é majoritariamente individual, notando-se o associativismo na comercialização da produção. Nos Estados do Sul e do Sudeste os beneficiários organizados em cooperativas ficam em torno de 20 a $30 \%$.

O relatório em si responde a certas preocupações dos gestores da reforma agrária e melhora, sem dúvida, o conhecimento sobre a situação dos assentamentos e dos assentados. No entanto, as estatísticas elaboradas em nível nacional, ou mesmo em nível estadual, são demasiadamente agregadas para se avaliar adequadamente os impactos da reforma em termos de ocupação do território. Em um país tão vasto e heterogêneo como o Brasil, considerar o processo de diferenciação espacial torna-se um elemento crucial na compreensão da reforma agrária.

\section{Metodologia dos mapas apresentados}

Com a perspectiva de realizar uma análise geográfica fina, propusemo-nos a efetuar uma nova exploração do conjunto das fichas do levantamento censitário (a pesquisa por amostragem não foi levada em consideração por razões de representatividade geográfica). Este trabalho foi feito por meio da utilização do programa Fox Pró (um gestor de base de dados para Macintosh), do SAS (Statistical Analisy System) para elaboração das estatísticas, do Cabral 500 e do Cabral Visão para a representação cartográfica, e do Adobe Illustrator para o acabamento dos mapas.

As tabulações pelo SAS foram programadas para produzir estatísticas sobre a base de 558 microrregiões geográficas, nível espacial intermediário entre os cinco mil municípios (nível muito desagregado levando em consideração a população em questão) e os 27 Estados (nível muito agregado ao se considerar suas dimensões). Todas as perguntas constantes do recenseamento foram objeto de tratamento, mas só uma parte delas foi escolhida: aquelas que apresentavam uma variação estatística conjugada com uma variação geográfica. Chegou-se, assim, a um conjunto de indicadores de natureza demográfica e sociológica.

Em razão da grande variabilidade da superfície das microrregiões geográficas, não se utilizou a técnica usual de mapas em variações de tonalidade (denomina- 
dos mapas coropléticos), em que a superfície de cada unidade espacial recebe uma cor relacionada com a variação estatística verificada na região. Um procedimento deste tipo aplicado ao Brasil conduz, quase sempre, a uma superestimação da importância das regiões mais extensas, ainda que se trate, na maioria das vezes, de regiões menos populosas (a Amazônia, por exemplo).

Assim, em todos os mapas deste trabalho a população (em geral, número de beneficiários da reforma agrária) é representada por um círculo localizado no centro da microrregião, e cuja superfície é proporcional à população. Mesmo quando os círculos se superpõem, limitando a leitura individual de cada valor, o efeito visual resultante (aquele que finalmente se deseja obter com este tipo de mapa) traduz satisfatoriamente o fenômeno de concentração. Em certos mapas, foram utilizados círculos brancos e pretos para representar uma mesma população, o que permite avaliar corretamente sua distribuição espacial (este é o caso do número total de beneficiários segundo o lugar de assentamento e o lugar de nascimento, e também do número de assassinatos e de ocupação de terras). Estes mapas são bastante simples, mas sua reprodução não é desejável, pois o nível de informação que eles transmitem é relativamente pobre. Preferiu-se, de uma maneira geral, recorrer a uma cartografia mais elaborada, por meio da utilização de cores.

Colorir os círculos equivale a agregar à quantidade cartográfica (a população) uma qualidade, em que a variabilidade dos valores se traduz na variabilidade das cores. Esta qualidade pode ser uma simples relação, como no caso da porcentagem dos beneficiários não residentes em suas parcelas ou lotes, bem como aquela dos beneficiários em situação irregular. Essas relações efetivos/porcentagens conduzem a uma leitura ponderada do mapa, agregando ao efetivo de uma variável particular (representado pela superfície do círculo) a sua participação relativa (porcentagem) na população total da qual esta variável faz parte.

Recorre-se, ainda, aos círculos coloridos para representar as classes contidas em uma classificação multivariada, como é o caso das repartições por idade dos beneficiários, seu nível de escolaridade ou o ano de ocupação da terra. Simultaneamente, utilizou-se a técnica do diagrama triangular (ou árvore de classificação), com o propósito de levar em consideração o conjunto de modalidades de cada variável reagrupada em três categorias por microrregião. Assim, cada microrregião se viu dotada de uma cor específica, representando a classe da qual ela faz parte. O círculo da microrregião foi, então, colorido com esta tonalidade. Chega-se, assim, a um mapa de síntese, que proporciona muito mais informações que um mapa em círculos brancos e pretos, mas que também é mais difícil de ler devido à necessidade de comparação constante entre o diagrama triangular e o mapa.

Todas essas técnicas de representação cartográfica de dados estatísticos são bem conhecidas. Isto, no entanto, não impede que freqüentemente sejam publicados mapas de má qualidade, como, por exemplo, os intitulados A geografía dos assentamentos rurais do Brasil, publicados (em cores) por pesquisadores da Unesp e da USP com base nos dados de 1994 do Incra e do Movimento dos Trabalhadores 
Rurais Sem Terra. Nesses mapas, os efetivos não foram expressos por símbolos proporcionais e as cores não foram ordenadas em gamas crescentes representando os efetivos. Em tais condições, a leitura global dos mapas torna-se impossível. A apresentação de uma simples tabela de dados teria sido, neste caso, bem melhor.

Todos os mapas aqui apresentados foram concebidos de acordo com os princípios da cartografia temática estatística e permitem apresentar um panorama bem completo (o mais completo possível, tendo em vista o que o recenseamento permite fazer) da situação dos beneficiários da política de reforma agrária do governo.

\section{A implantação dos assentamentos no espaço e no tempo}

Os assentamentos não apresentam uma distribuição geográfica uniforme sobre o conjunto do território nacional (mapa 1$)$.

A questão da reforma agrária atinge o país em seu conjunto - nenhum Estado foi poupado deste problema - mas observa-se que as regiões Sudeste e Sul aparecem de forma pouco expressiva na política agrária. Ainda que exista nos Estados do Rio de Janeiro, Santa Catarina, Rio Grande do Sul e, sobretudo, no interior menos desenvolvido do Paraná uma relativa concentração de explorações agrícolas criadas por meio de projetos do Incra, seu número ainda é pouco significativo se comparado às outras regiões do país (menos de $2 \%$ do total em cada um desses Estados).

Os projetos do Incra se desenvolveram, principalmente, segundo dois eixos principais. O mais importante (cerca de 40 mil explorações, $25 \%$ do total), no oeste do Maranhão e no norte do Mato Grosso. Correspondendo, inicialmente, ao traçado da rodovia BR 158 até Marabá (e daí para o norte em direção a Tucuruí, BR 230), depois este eixo se orienta para o Nordeste, mais especificamente para o Maranhão, seguindo o traçado da ferrovia que liga Carajás a São Luís. O segundo eixo de desenvolvimento dos projetos do Incra (cerca de 30 mil explorações, 18\% do total) segue a rodovia federal que liga Campo Grande a Rio Branco, ou seja, o oeste do Mato Grosso do Sul ao sul do Acre. Nesses dois eixos de implantação, o ano de ocupação é normalmente posterior a 1984 (mapa 2), e metade das instalações são recentes (criadas depois de 1991). Este movimento prosseguiu, com uma intensidade menor, no Mato Grosso, e seguindo as vias de comunicação que ligam Porto Alegre a Manaus e Boa Vista: aqui, $87 \%$ dos perímetros ocupados o foram depois de 1991.

Assim, quase metade dos assentamentos foram realizados no espaço pioneiro do oeste do país. A marcha para o oeste não se limita aos assentamentos realizados pelo Incra, mas pode-se verificar que a política de instalação de agricultores coincide nesta parte do país com a frente de ocupação. O recenseamento agropecuário realizado pelo IBGE em 1996 permitirá uma melhor avaliação da participação dos assentamentos no total das exportações agropecuárias dessas regiões, que se encontram em rápido processo de transformação. 
Mapa 1

Número de assentamentos em 1996

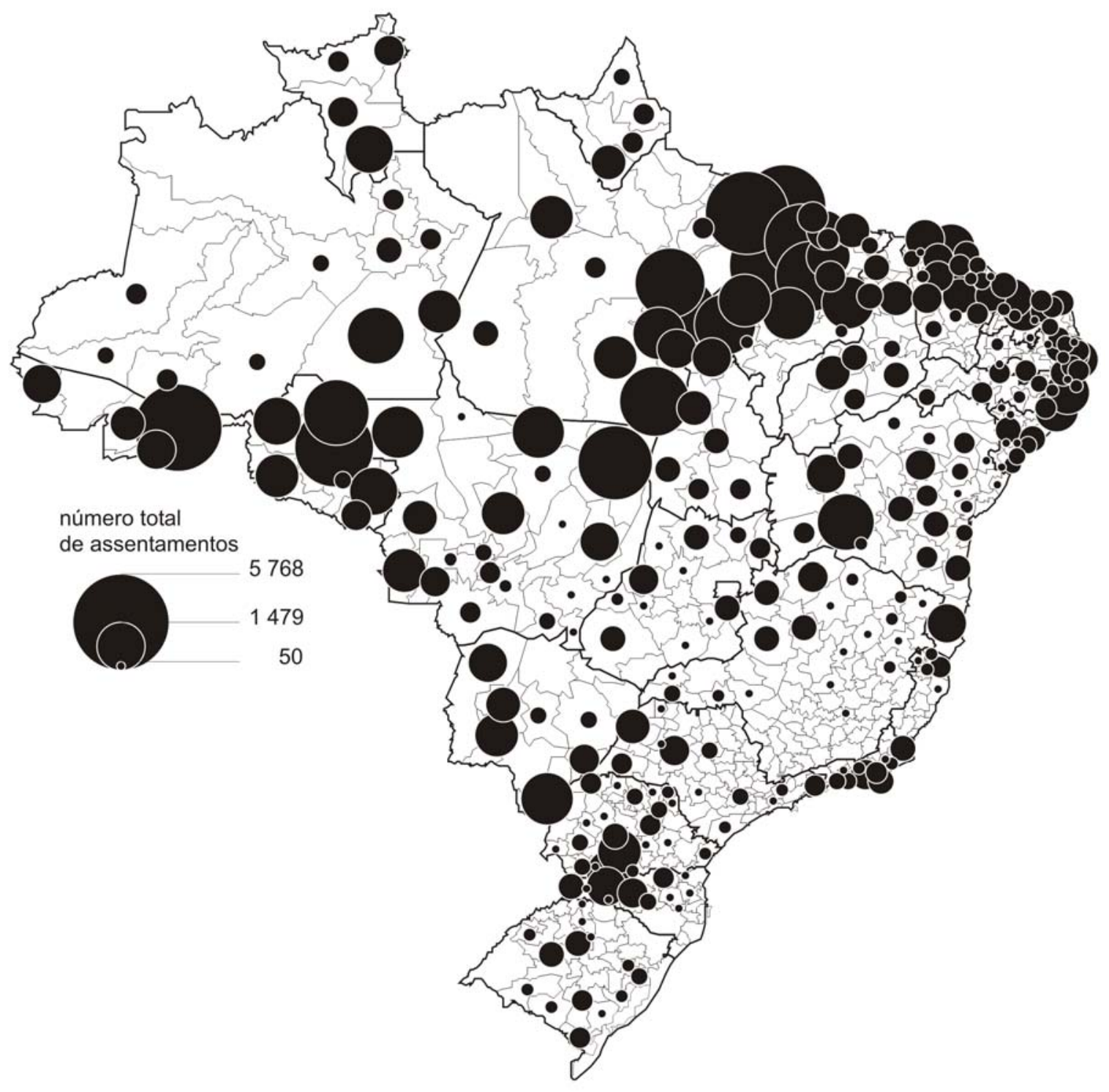

Fonte: I Censo da Reforma Agrária do Brasil - 1996 
Mapa 2

Ano de ocupação da área pelos beneficiários
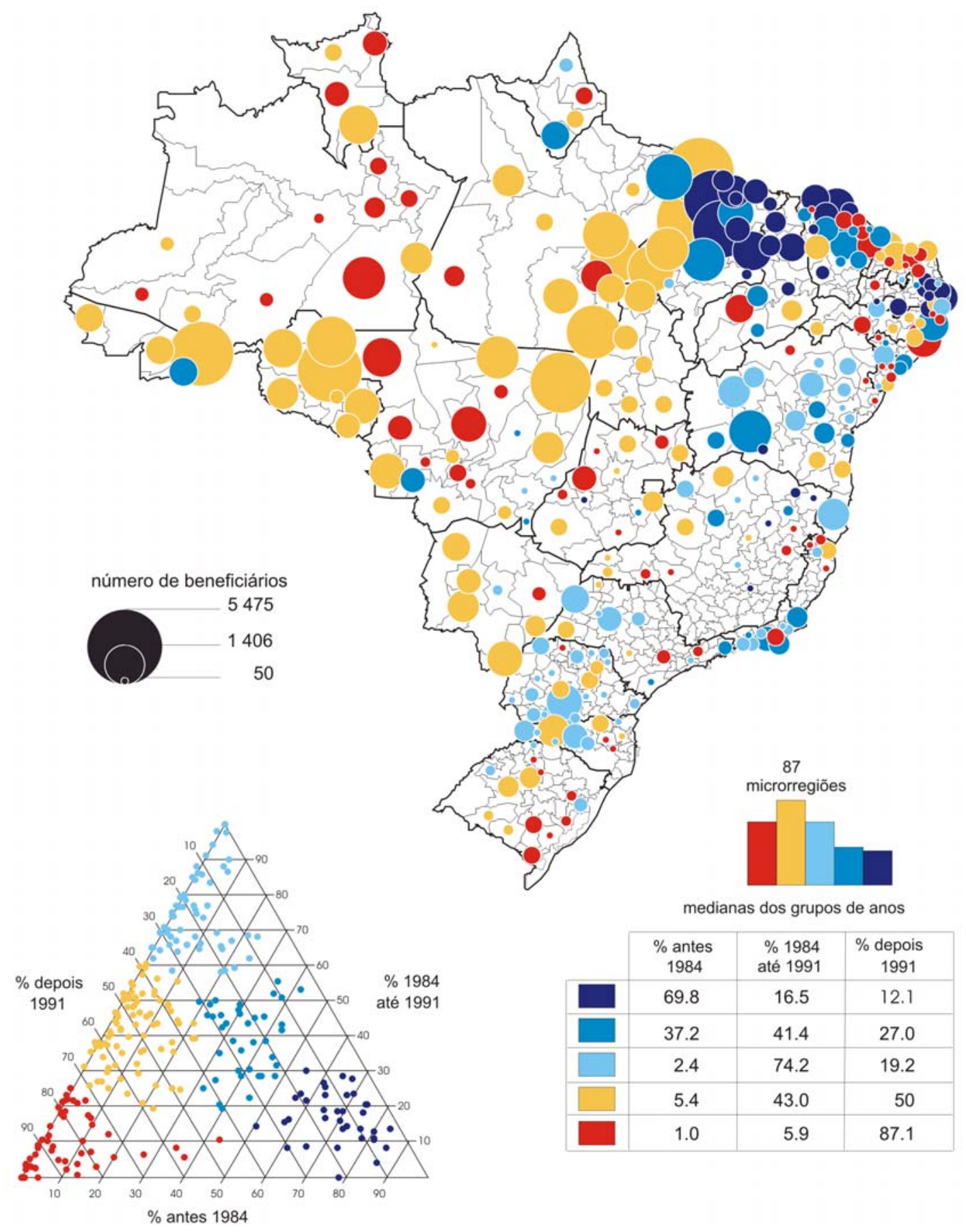

medianas dos grupos de anos

\begin{tabular}{|c|c|c|c|}
\multicolumn{4}{|c|}{ medianas dos grupos de anos } \\
\cline { 2 - 4 } & $\begin{array}{c}\% \text { antes } \\
1984\end{array}$ & $\begin{array}{r}\% 1984 \\
\text { até } 1991\end{array}$ & $\begin{array}{c}\% \text { depois } \\
1991\end{array}$ \\
\hline & 69.8 & 16.5 & 12.1 \\
\hline & 37.2 & 41.4 & 27.0 \\
\hline & 2.4 & 74.2 & 19.2 \\
\hline & 5.4 & 43.0 & 50 \\
\hline & 1.0 & 5.9 & 87.1 \\
\hline
\end{tabular}

Fonte: I Censo da Reforma Agrária do Brasil- 1996 
A concentração dos projetos do Incra no Nordeste reflete uma agricultura regionalizada: a franja litorânea e o agreste são os mais beneficiados, ao passo que o sertão fica marginalizado. O interior da Bahia, ao contrário, com 3.500 instalações, aparece com uma melhor distribuição. No total, o conjunto da região Nordeste reúne quase 65 mil implantações. O Maranhão agrupa mais de 40\% (27 mil implantações), seguido de longe pelo Ceará e a Bahia.

Se uma parte do Maranhão participa ativamente da expansão da frente pioneira leste-amazoniana, a dinâmica do resto do Estado se assemelha mais àquela da região. De fato, as implantações são, na sua grande maioria, anteriores a 1984. Essas correspondem freqüentemente àquelas dos perímetros ditos regularizados, isto é, ocupados antes de serem incluídos nos projetos de reforma agrária. Por exemplo, na Paraíba, 22\% dos beneficiários ocuparam suas terras antes de 1960, sendo que no Ceará este porcentual corresponde a $17 \%$ e no Piauí a 13\%. Encontram-se no Nordeste, também, instalações recentes, posteriores a 1991, notadamente no Ceará e no Rio Grande do Norte, que provam que o acesso dos nordestinos à terra não é um problema resolvido pelo desenvolvimento das frentes de colonização.

\section{Os níveis de formação}

Os beneficiários foram divididos em três grupos por nível de escolaridade: analfabetos, alfabetizados até a $2^{a}$ série do primeiro grau e da 3 a série do primeiro grau em diante. O nível de formação dos beneficiários é, globalmente, muito ruim: cerca de $30 \%$ deles são analfabetos. Apesar desta tela de fundo ser muito preocupante, observam-se diferenças regionais marcantes no Sul e na frente pioneira do oeste, especialmente nos estados de Mato Grosso e Rondônia (mapa 3).

Existem duas populações diferentes de beneficiários do ponto de vista do nível de formação: os nordestinos e os outros. Pode-se verificar que, no Ceará, mais de $60 \%$ dos beneficiários são analfabetos. Mesmo sem atingir este extremo, o resto do Nordeste permanece em uma situação deplorável: a taxa de analfabetos entre os beneficiários não se situa, a não ser excepcionalmente, abaixo de $30 \%$.

Nos demais Estados os níveis de formação são mais diferenciados. São melhores no Sul do que na frente pioneira do Pará, onde o mau desempenho pode ser explicado pela grande participação de nordestinos. No eixo de colonização do oeste, o Mato Grosso do Sul situa-se em uma posição intermediária, mas não muito boa. Em compensação, o desempenho do Mato Grosso e de uma parte de Rondônia é impressionante: nestas áreas, a maioria das microrregiões se caracterizam por uma proporção de beneficiários com nível de escolaridade elevado, superior a 50\%. A situação encorajante da frente pioneira do oeste, no que se refere ao nível de escolaridade, é complementada pela capacidade de seus beneficiários de exercerem uma outra profissão além da de agricultor ou camponês ( $80 \%$ das respostas à questão sobre a atividade principal). É precisamente no Mato Grosso que os agricultores se declaram freqüentemente capazes de exercer outra atividade. No Nordeste, a porcentagem de respostas positivas é a mais baixa do país. 
Mapa 3

Nível de escolaridade do beneficiário
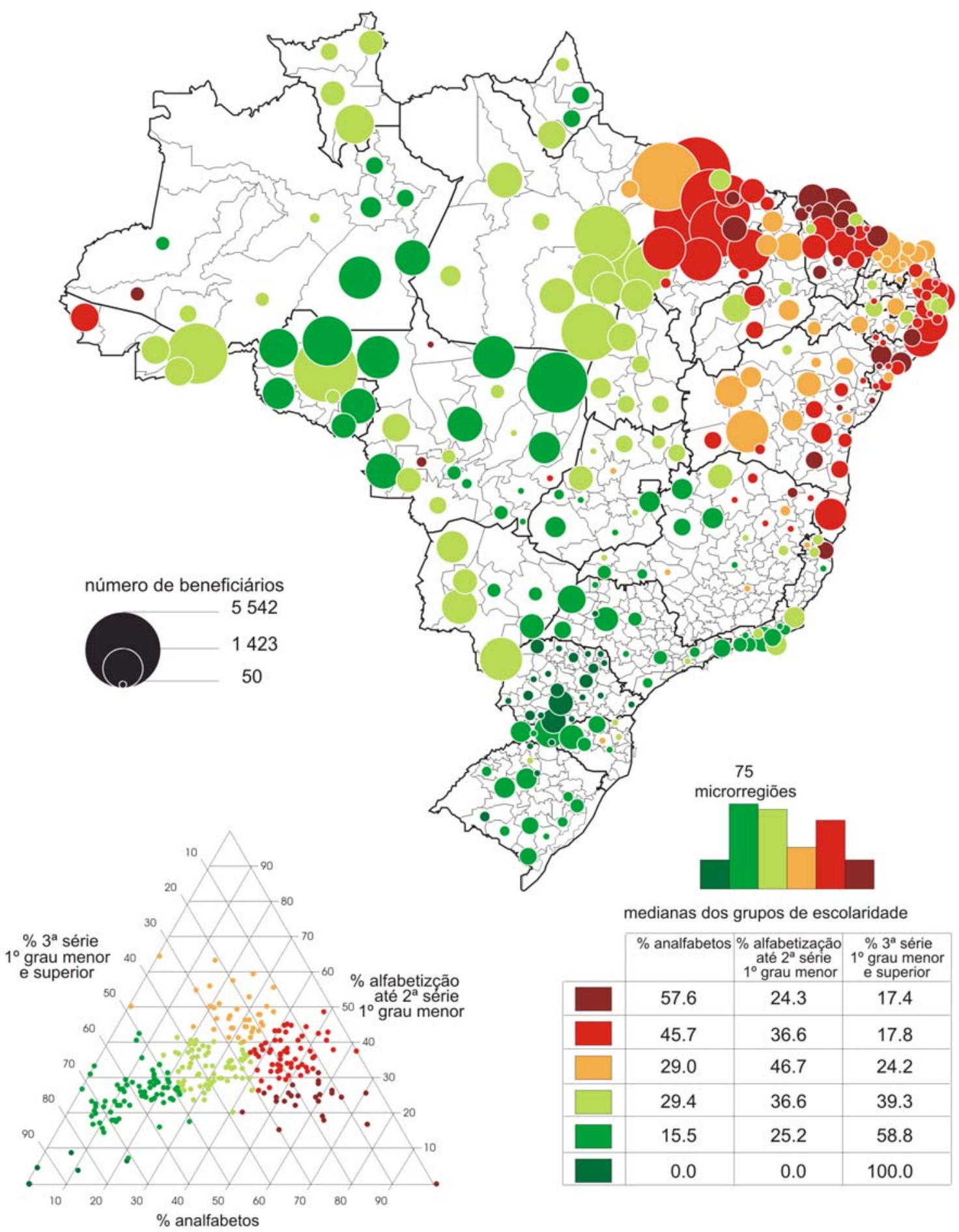

\begin{tabular}{|c|c|c|}
\hline$\%$ analfabeto & $\begin{array}{c}\% \text { alfabetização } \\
\text { até } 2^{\mathrm{a}} \text { série } \\
1^{\circ} \text { grau menor }\end{array}$ & $\begin{array}{l}\% 3^{\mathrm{a}} \text { série } \\
1{ }^{1} \mathrm{~g} \text { grau menor } \\
\text { e superior }\end{array}$ \\
\hline 57.6 & 24.3 & 17.4 \\
\hline 45.7 & 36.6 & 17.8 \\
\hline 29.0 & 46.7 & 24.2 \\
\hline 29.4 & 36.6 & 39.3 \\
\hline 15.5 & 25.2 & 58.8 \\
\hline 0.0 & 0.0 & 100.0 \\
\hline
\end{tabular}

Fonte: 1 Censo da Reforma Agrária do Brasil- 1996 


\section{Ocupações de terra \\ e vítimas fatais da violência no campo}

A análise das características dos beneficiários da política de reforma agrária praticada pelo Incra mostra claramente que alguns resultados significativos foram obtidos. No entanto, esses resultados são insuficientes em termos quantitativos e qualitativos.

Sobre o plano quantitativo, ou seja as condições de vida, econômicas e sociais dos beneficiários, o recenseamento apresenta dados relativamente pouco expressivos, ainda que a pesquisa por amostragem realizada concomitantemente aporte um conjunto de informações bem agregadas e, portanto, não-regionalizáveis. Uma amostragem permite a estimação de valores desconhecidos em relação a uma população delimitada. No caso da pesquisa realizada em conjunto com o censo, a repartição dos assentamentos entre os Estados serviu como fator de estratificação na elaboração da amostragem. Portanto, não é legítimo analisar os dados provenientes da amostra em nível de município ou mesmo de microrregiões. Devem se limitar à análise por Estados, unidades para as quais ela foi elaborada.

Para avaliar a política de reforma agrária face à demanda social, recorreu-se a informações adicionais, que não foram coletadas no recenseamento. Há alguns anos, a Comissão Pastoral da Terra (CPT) da Conferência Nacional dos Bispos do Brasil (CNBB) realiza levantamentos estatísticos muito relevantes, especialmente sobre dois fenômenos muito significativos: as ocupações de terras pelos agricultores semterra e os assassinatos ligados aos conflitos pela posse da terra.

Em onze anos, de 1985 à 1996, a CPT registrou 966 assassinatos relacionados a conflitos fundiários. O número de vítimas vinha diminuindo com o decorrer

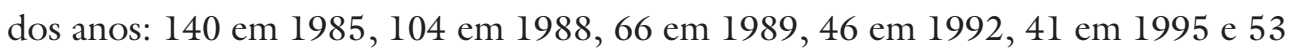
em 1996, situação que não se verificou no último ano. A tendência é claramente de diminuição, mas o número de assassinatos é ainda inadmissível para um país democrático. Eles ocorrem em todo o país ( mapa 4), mas a região mais afetada permanece sendo a Amazônia, em particular o oeste do Maranhão e o leste do Pará. Em segundo lugar está a região que abrange o norte do Mato Grosso e o Estado de Rondônia. Esta localização nos remete àquela detectada como sendo de concentração dos beneficiários em situação irregular. Pode-se constatar, claramente, que a política governamental atende apenas parcialmente às demandas, o que acaba por se traduzir em processos de violência como o de Eldorado de Carajás, que comoveu o país em 1996.

As ocupações de terras constituem um outro fato revelador das mazelas provocadas pelas insuficiências da reforma agrária. Seu número é crescente, passando de 8.200 famílias, em 1990, para 20 mil, em 1995, e 63 mil, em 1997. Ainda que o movimento seja claramente crescente, deve-se utilizar esses indicadores com precaução, pois eles não são resultado de um levantamento sistemático, mas somente indicações, às vezes fluidas, comunicadas pelos próprios interessados. 
Mapa 4

Vítimas fatais de conflitos ocorridos no campo 1985-1996

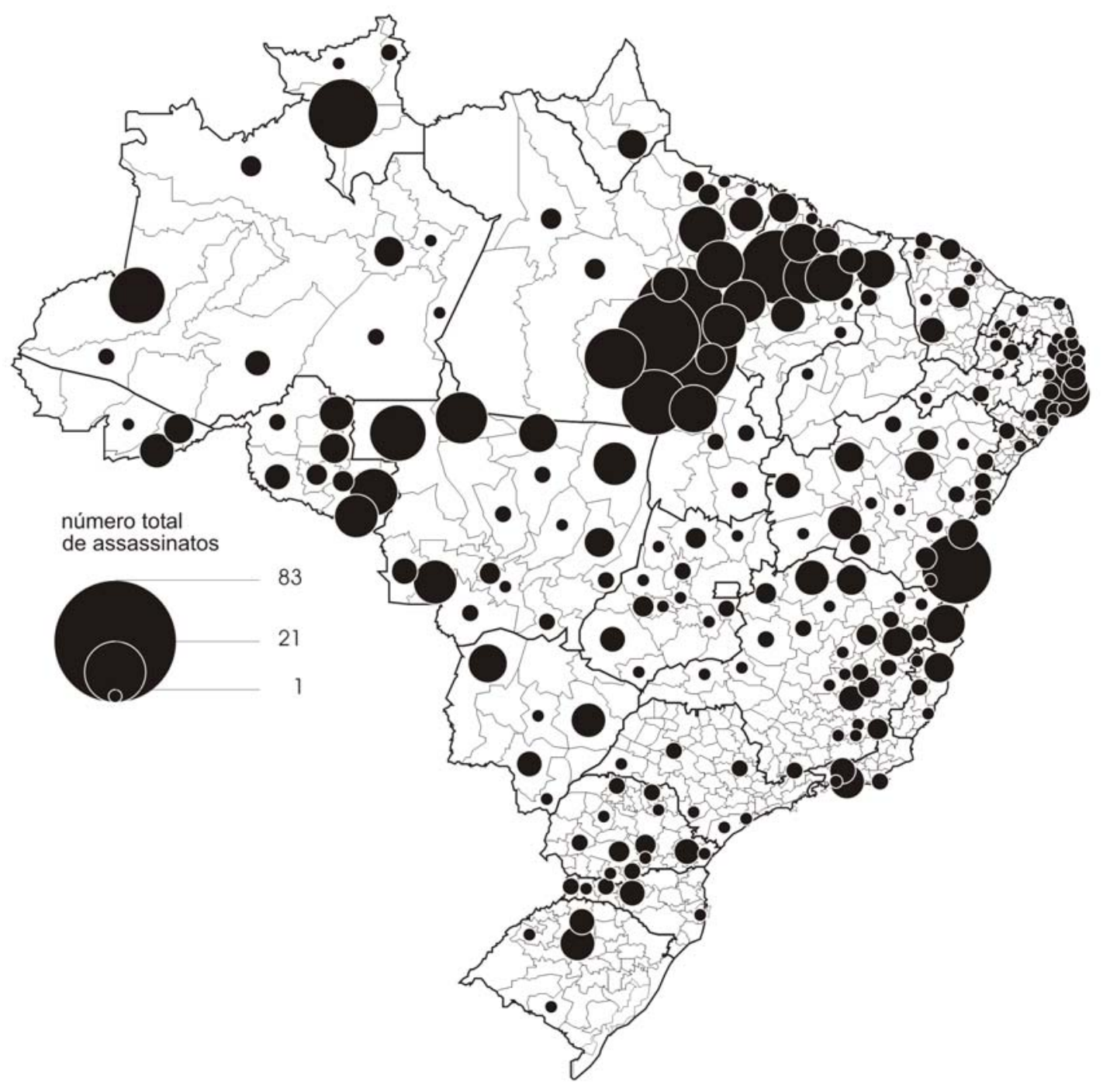

Fonte: Comissão Pastoral da Terra - CPT 
Mapa 5

Ocupação de terras 1996

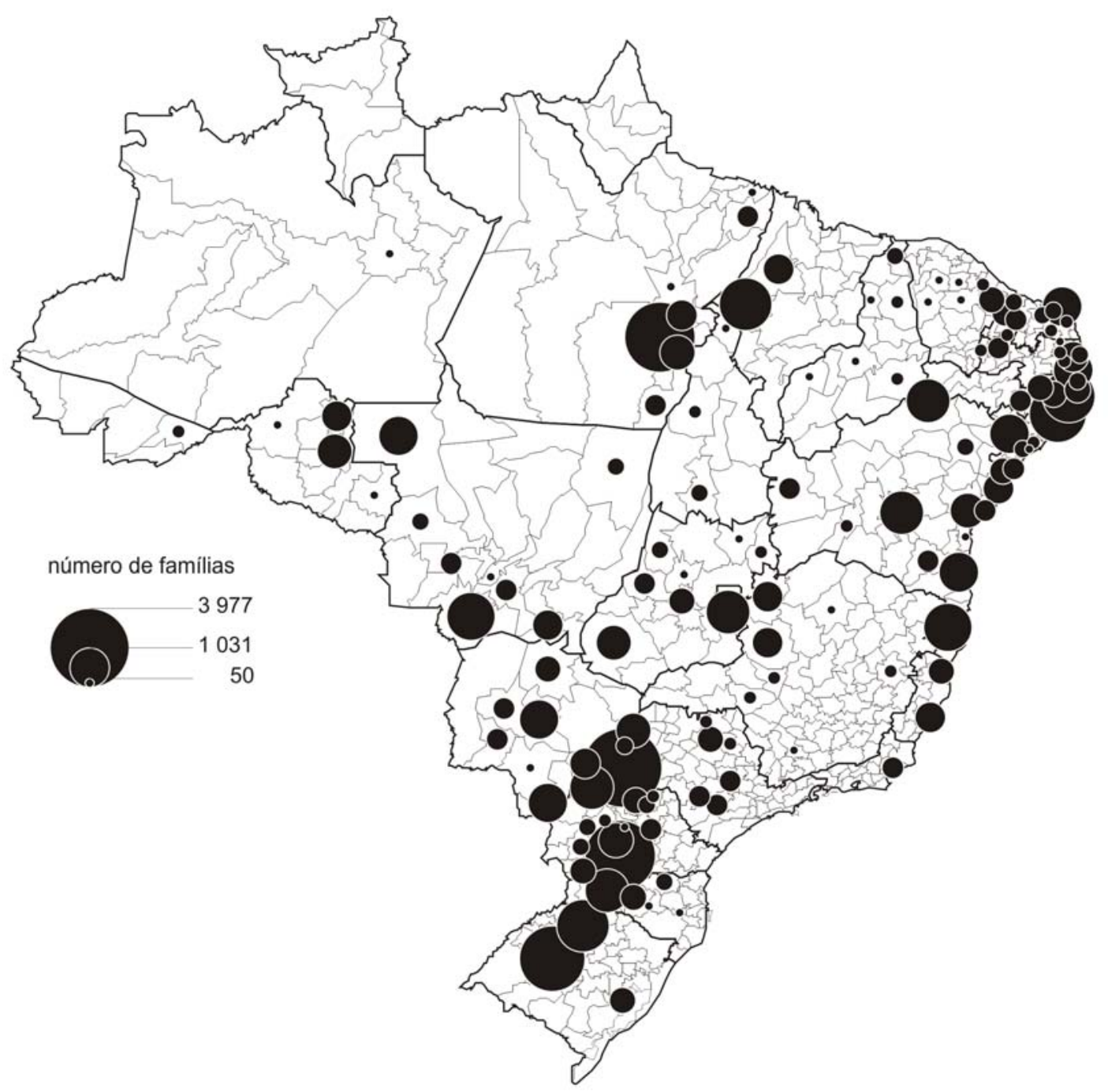

Fonte: Comissão Pastoral da Terra - CPT

Estudos Avancados (11) 31, 1997 
O mapa das ocupações em 1996 ( mapa 5) apresenta uma configuração original, com uma concentração nas regiões sul e nordeste do país. Podemos ver a escolha dos camponeses que recusaram a fuga em direção à Amazônia, preferindo lutar onde estão para obter uma parcela de terra a qual eles crêem ter direito. Observa-se, assim, as limitações da política governamental: a marcha em direção ao oeste demonstra seus limites, ao passo que as tensões acumuladas nas outras regiões estão provocando uma grave crise política e social com conseqüências de difícil avaliação.

\section{Algumas informações oriundas da amostra}

A pesquisa por amostragem, mesmo não podendo ser utilizada para os propósitos deste trabalho, apresenta alguns resultados interessantes. Destacam-se os dados relativos à atividade do beneficiário, grau de associativismo, técnicas agrícolas utilizadas, renda média, condições de habitação e saúde dos assentados e principais produtos agropecuários produzidos nos assentamentos. No que se refere à atividade anterior dos beneficiários (gráfico 1), verifica-se que uma grande parte destes já trabalhava na agricultura (cerca de $54 \%$ como agricultores e camponeses e mais de $8 \%$ como trabalhadores rurais). Os dados a respeito do grau de associativismo (gráfico 2), medido pela participação dos beneficiários em diferentes organizações sociais, revelam que uma grande parte dos assentados do país $(53,27 \%)$ envolvidos com alguma associação apresentam estreita relação com a Igreja. As regiões seguem este mesmo padrão nacional, com exceção do Sudeste, onde predomina a participação dos assentados em associa- ções diversas. Como um mesmo beneficiário pode participar de mais de uma associação, as respostas neste quesito da amostra não são excludentes e, portanto, a soma das freqüências relativas de cada variável pode ultrapassar $100 \%$.

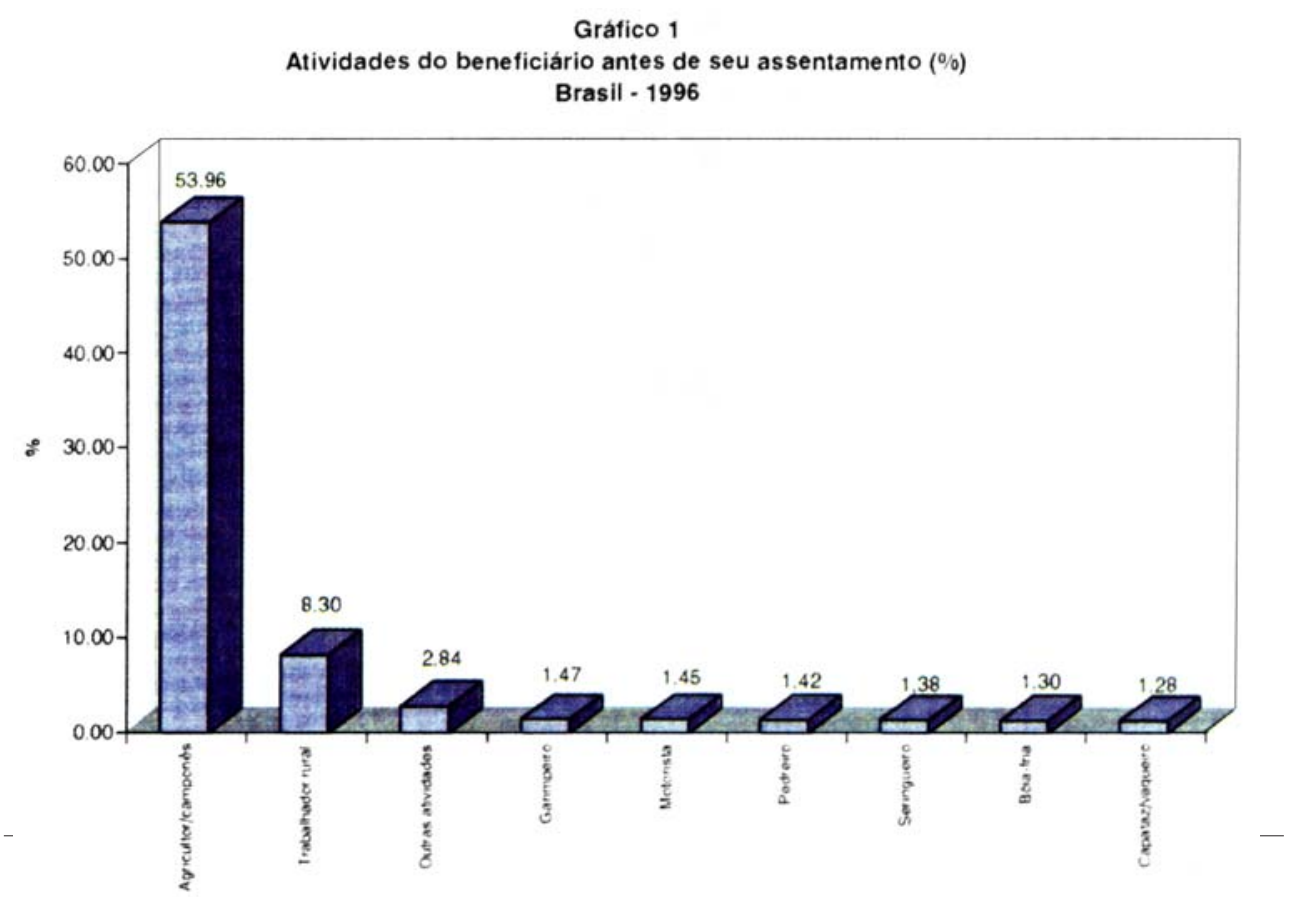




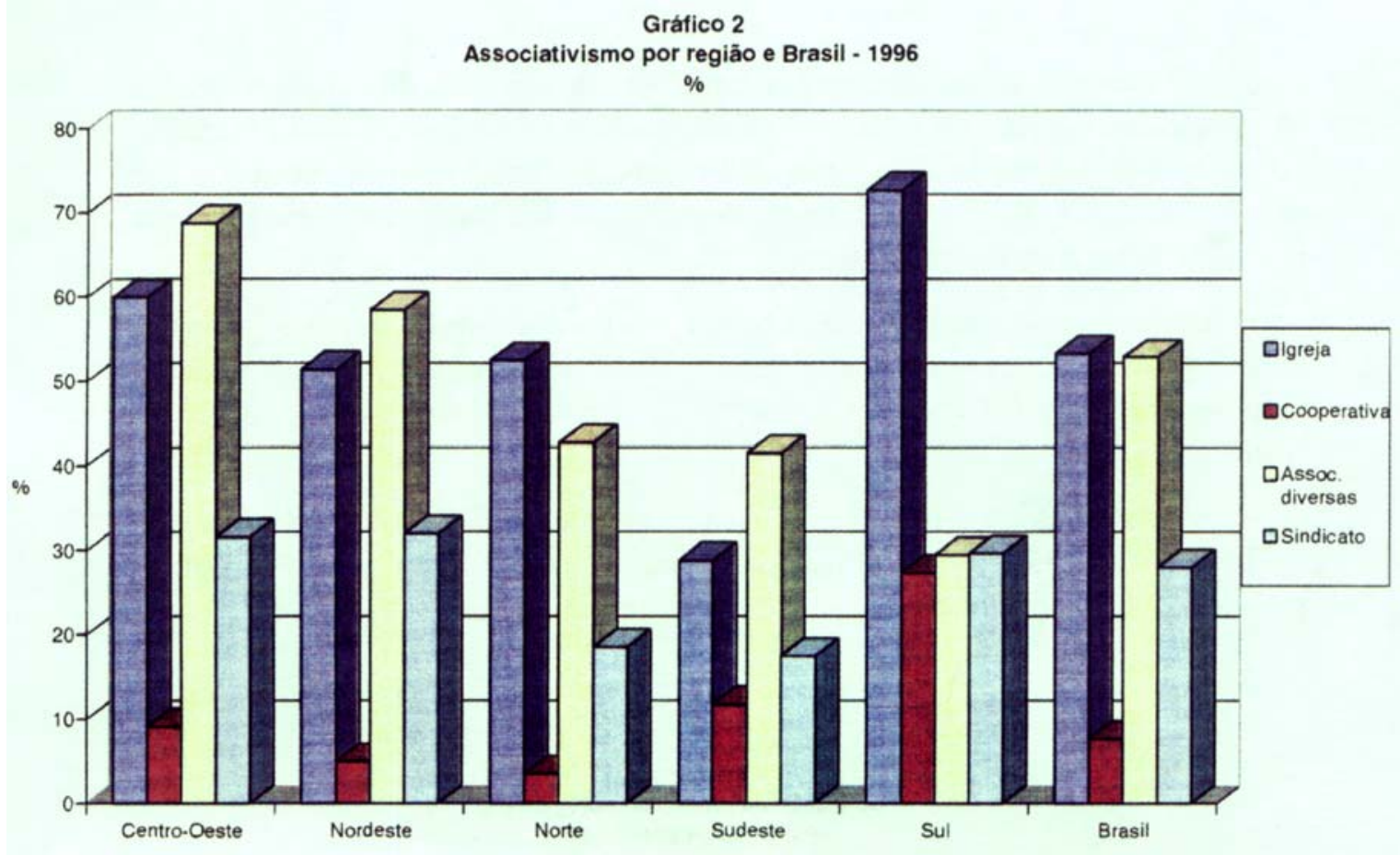

O levantamento dos dados sobre a utilização de técnicas agrícolas modernas (gráfico 3) verificou que esta ocorre com maior freqüência na região Sul, seguida do Sudeste.

Quanto à assistência técnica prestada aos projetos de assentamentos, cerca de $34 \%$ dos beneficiários da região Sul consideram este serviço como de boa qualidade, contrastando com as regiões Norte, Centro-Oeste e Nordeste, onde tal assistência, em sua grande maioria, inexiste ou é de má qualidade. É importante destacar que a assistência técnica recebida pelos beneficiários é, majoritariamente, oriunda de órgãos governamentais.

Quanto à renda monetária média, a amostra revelou que esta supera dois salários mínimos mensais, e que as regiões Sudeste e Centro-Oeste apresentam, em valores monetários reais, a maior concentração de renda.

No que diz respeito ao acesso dos beneficiários a créditos governamentais, dados da amostra mostram que o Programa de Crédito Especial para Reforma Agrária (Procera) não tem funcionado como previsto, tanto para custeio como para investimento.

As condições de habitação e saúde são precárias e as enfermidades mais comuns estão relacionadas à inexistência de saneamento básico e à contaminação dos lençóis freáticos.

No que se refere à produção agrícola, em nível nacional, verifica-se que o milho é o produto cultivado que aparece com maior freqüência nos assentamentos. Outros produtos de destaque são: arroz, feijão, cana-de-açúcar, mandioca e café. 
Essa produção tem como destino, predominantemente, os intermediários (gráfico 4). Atacadistas e varejistas também são importantes compradores, ficando as cooperativas com uma parcela pouco significativa desta produção. A região Sul apresentase como exceção em relação ao resto do país, uma vez que a maior parte de sua produção destina-se às cooperativas.

Entre os produtos pecuários, observa-se a predominância das aves (galinhas, patos e perus, com estoque médio igual a 28,75 unidades por família), seguidas pelos ovinos, caprinos e suínos e, finalmente, pelos bovinos (estoque médio de quatro cabeças por família).

A inserção dos assentados no mercado ainda é precária, sobretudo pela dificuldade de escoamento da produção, pela baixa agregação de valor dos produtos por eles comercializados e pela escassez de financiamento.

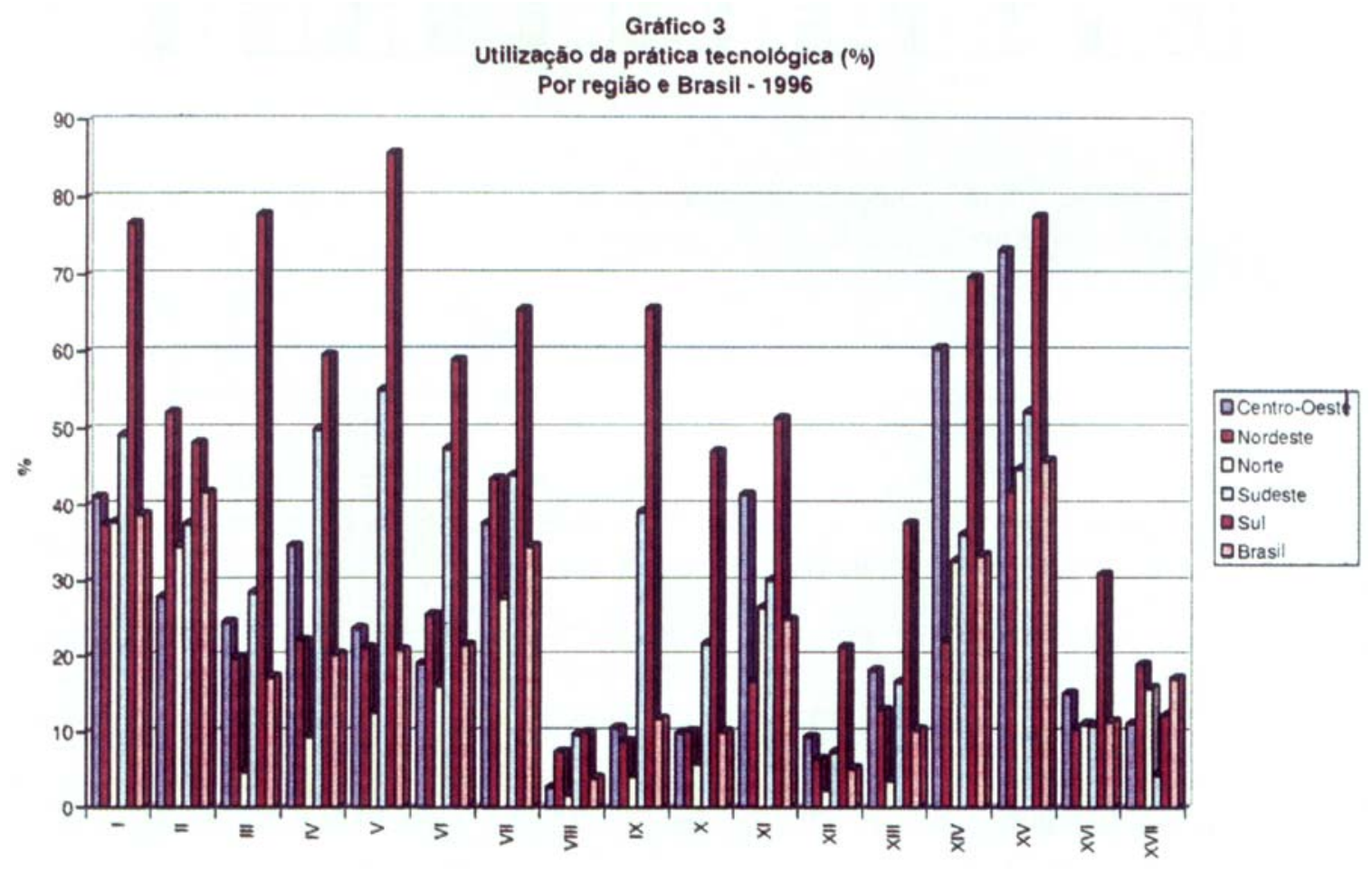

1 - Utilização de sementes ou mudas selecionadas

$\mathrm{XI}$ - Manejo racional das pastagens

II - Tratos culturais adequados

XII - Práticas de armazenamento e conservaçăo de

III - Uso de mecanizaçăo - Traçăo animal

IV - Uso de mecanizaçã̃o - Tração motora

forragens

XIII - Utilizaçã̃o de ração concentrada

V - Uso de adubação química

VII - Utilização de defensivos agrícolas

VIII - Práticas de irrigaçăo e drenagem

IX - Correção do solo

XIV - Mineralização

XV - Controle de sanidade animal

XVI - Práticas de melhoramento do rebanho

$\mathrm{X}$ - Práticas de conservaçã̃o do solo

XVII - Outro sistema de desenvolvimento próprio 


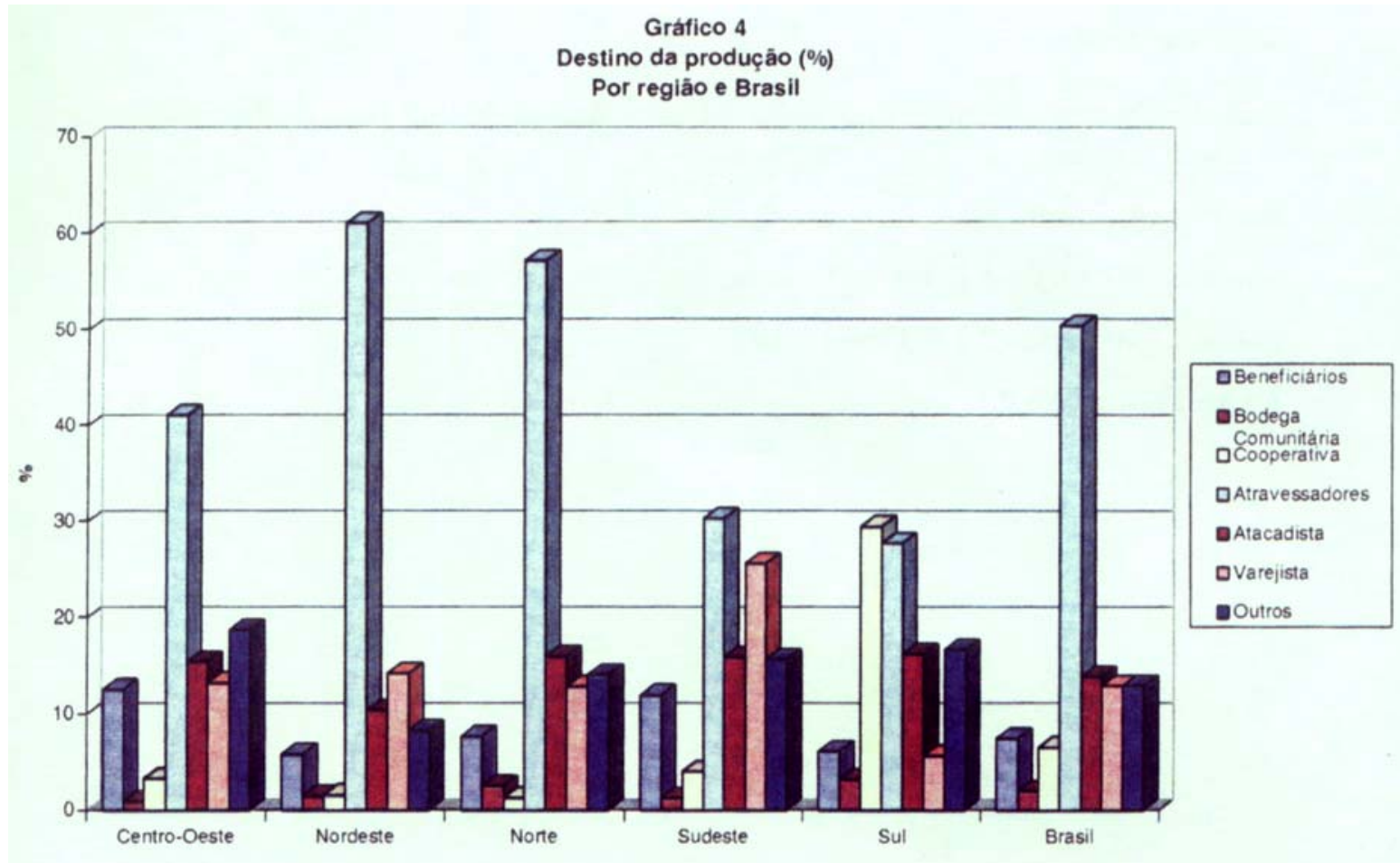

Notas

1 David, M. B. de A. “La modernisation 'perverse' de l'agriculture et la structure de la propriété de la terre au Brésil”. In: Cahiers du Brésil Contemporain, número especial. Paris: MSH/CRBC, 1995, p. 163.

2 Ibid.

3 Ibid.

4 Ibid.

5 Relatório de atividades do Incra, 1995.

6 Relatório de atividades do Incra, 1996.

Referências bibliográficas

I Censo da Reforma Agrária. Relatório Final. Brasília: Universidade de Brasília, maio de 1997.

DAVID, M. B. de A. "La modernisation 'perverse' de l'agriculture et la structure de la propriété de la terre au Brésil”. In: Cahiers du Brésil Contemporain, número especial. Paris: MSH/CRBC, 1995. 
Softwares usados

Statistical Analisy System (SAS), versão 6.1 para Macintosh, SAS Institute Inc. Cary, North-Carolina.

Fox Pro, Microsoft.

Samba 2.000, versão 4.1, IBGE/Orstom, 1997.

Cabral 1.500, versão 2.1.7, Orstom, 1997.

Adobe Illustrator 6.0.

Maria Beatriz de Albuquerque David é pesquisadora do Ipea (Instituto de Pesquisa Econômica e Aplicada) e professora-adjunta da Faculdade de Economia da UERJ .

Philippe Waniez é pesquisador da Orstom (Instituto de Pesquisa Científica para o Desenvolvimento em Cooperação da França)

Violette Brustlein é integrante da Credal-CNRS (Conselho Nacional de Pesquisa Científica da França).

Os autores agradecem a colaboração de Dora Rodrigues Hess e das estagiárias do Ipea, Mônica Rodrigues e Paula Rollo, e os comentários e sugestões feitos por Maurício Dias David (BNDES) a uma versão preliminar deste trabalho. 